to catecholamines then a postsynaptic receptor-blocking drug such as propranolol would produce a depressor action. Schley et al. (1970) have shown an increase in urinary excretion of catecholamine metabolites in patients with acute intermittent porphyria during an attack, and this is probably a reflection of increased circulating levels of catecholamines. In the present study the urinary excretion of catecholamines was increased in both patients in whom the measurement was made. It is also possible that changes in receptor site sensitivity to circulating catecholamines could occur in the presence of lesions of the sympathetic nerves. Such lesions are known to exist in acute intermittent porphyria (Gibson and Goldberg, 1956).

Evaluation of the efficacy of drug treatment in acute intermittent porphyria is particularly difficult because of the relapsing and remitting course of the disease. This feature, together with the comparative rarity of the porphyrias, precludes the controlled clinical trial method of assessment. In the four patients described administration of propranolol seemed to be followed closely by a reduction in both heart rate and blood pressure and in one case (case 2) control of abdominal pain. At the same time the patients' general condition seemed to improve. On the basis of animal studies it is believed that propranolol will not aggravate the attack.

\section{References}

Dowdle, E. B., Mustard, P., and Eales, L. (1967). South African Medical fournal, 41, 1093.

Gibson, J. B., and Goldberg, A. (1956). Fournal of Pathology and Bacteriology, $71,495$.

Goldberg, A. (1959). Quarterly fournal of Medicine, N.S., 28, 183.

Granick, S. (1966). Fournal of Biological Chemistry, 241, 1359.

Le Roux, D. (1963). South African fournal of Laboratory and Clinical Medicine, 9, 308.

Marver, H. S., Tschudy, D. P., Perlroth, M. G., and Collins, S. (1966). fournal of Biological Chemistry, 241, 2803.

Mauzerall, D., and Granick, S. (1956). fournal of Biological Chemistry, 219, 435.

Melkersson, E. (1925). Acta Medica Scandinavica, 63, 153

Moore, M. R., Battistini, V., Beattie, A. D., and Goldberg, A. (1970), Biochemical Pharmacology, 19, 751.

Moore, M. R., Beattie, A. D., Thompson, G. G., and Goldberg, A. (1971). Clinical Science, 40, 81 .

Pisano, J. J. (1960). Clinica Chimica Acta, 5, 406

Rimington, C. (1961). Association of Clinical Pathologists, Broadsheet, No. 36 Schley, G., et al. (1970). Klinische Wochenschrift, 41, 36.

Tschudy, D. P., et al. (1965). Proceedings of the National Academy of Sciences $53,841$.

Waldenström, J. (1937). Acta Medica Scandinavica, Suppl. No. 82.

\title{
Foot Infections in Swimming Baths
}

\author{
J. C. GENTLES, E. G. V. EVANS
}

British Medical fournal, 1973, 3, 260-262

\section{Summary}

A $10 \%$ random sample of all bathers at a public swimming bath were examined for tinea pedis and verruca.

The overall incidence of tinea pedis was $8.5 \%$ and of verruca $4.8 \%$. The incidence of tinea pedis in 205 male adults was $21.5 \%$, in 288 boys $6.3 \%$, in 60 adult females $3.3 \%$, and in 220 girls $0.9 \%$. The incidence of verruca in juveniles ranged from $4.2 \%$ in boys to $10.5 \%$ in girls.

It was clear that both infections spread within the baths, and since a relatively small proportion of users admitted to taking precautions to avoid contracting or developing infections it seems advisable that more publicity about recommendations on foot care should be provided.

\section{Introduction}

The role of communal bathing places such as indoor swimming pools in the spread of foot infections has been well established. The incidence of infection in bathers at such establishments, however, has never been fully investigated nor have there been many attempts to determine a procedure which might minimize the risk to bathers. This paper presents the results of an investigation of the incidence of infections with dermatophytes (tinea pedis) at a new swimming pool in the West of Scotland before the introduction of a procedure aimed at reducing the spread of infection. The incidence of verruca was also noted.

\footnotetext{
Department of Dermatology, University of Glasgow, Glasgow G11 6NU

J. C. GENTLES, B.SC., PH.D., Reader in Medical Mycology

Departments of Dermatology and Microbiology, University of Leeds, and General Infirmary at Leeds, Leeds LS1 3EX

E. G. V. EVANS, B.SC., Lecturer in Medical Mycology
}

\section{Methods}

The swimming bath is a covered, heated, international-class pool opened 18 months before the survey. An average of 8,000 bathers enter the pool each week, a large number of whom are visitors from surrounding townships. On entry those under 16 years of age are classified as juveniles.

A $10 \%$ random sample of bathers was selected by means of an electronic counting machine from those using the pool over a period of one week. The selected bathers were first interviewed and personal details including swimming habits were recorded on specially prepared cards. Their feet were examined and their clinical condition, including the presence of any verrucae, noted. Scrapings were taken, whenever possible, from the 4th toe clefts of both feet and from any other clinically suspicious sites. In most cases the material collected from each subject was pooled. When the skin of the toe clefts was so smooth that it was impossible to collect material without inducing trauma the bather was regarded as clear of infection.

Samples were processed using routine methods for laboratory diagnosis of superficial fungal infections-namely, culture on $4 \%$ malt extract agar of 12 inocula at $28^{\circ} \mathrm{C}$ and direct microscopy in $20 \%$ potassium hydroxide.

The statistical validity of the results was assessed using the $\chi^{2}$ test.

\section{Results}

A summary of the results is shown in table I. A total of 8,291 bathers entered the pool during the sampling week and of these $773(9.3 \%)$ were interviewed and examined. A further 75 were selected but either did not appear for examination or refused.

Of the 773 persons examined a specimen could not be obtained from $118(15 \%)$ and on a further 226 (29\%) occasions the material that could be obtained was insufficient to allow either the full number of inocula for culture or micros- 
TABLE I-General Results of Survey

\begin{tabular}{|c|c|c|c|c|}
\hline & \multirow{2}{*}{ Baths Entry } & \multirow{2}{*}{ Sample } & \multicolumn{2}{|c|}{ No. Infected } \\
\hline & & & Tinea Pedis & Verruca \\
\hline $\begin{array}{l}\text { Overall total } \\
\text { Adults ( }>16 \text { years) } \\
\text { Juveniles ( }<16 \text { years) }\end{array}$ & $\begin{array}{l}8,291 \\
2,172 \\
6,119\end{array}$ & $\begin{array}{l}773(9 \cdot 3 \%) \\
265(12 \cdot 2 \%) \\
508(8 \cdot 3 \%)\end{array}$ & $\begin{array}{l}66(8.5 \%) \\
46(17 \%) \\
20(3.9 \%)\end{array}$ & $\begin{array}{l}37(4.8 \%) \\
2(0.76 \%) \\
35(6.9 \%)\end{array}$ \\
\hline
\end{tabular}

copical examination. Thus complete laboratory examination was done for $429(56 \%)$ subjects. The infection rates may therefore be slightly higher than indicated, though clearly those from whom it was not possible to obtain an adequate specimen are less likely to be infected.

The overall incidence of tinea pedis proved by laboratory investigation was $8.5 \%$, being more prevalent among adults (17\%) than juveniles $(3.9 \%)(P=<0.001)$. For verruca the overall incidence was $4.8 \%$ with the incidence in adults and juveniles of $0.76 \%$ and $6.9 \%$ respectively $(P=<0.001$ ). There were also differences in infection rates according to sex (table II). There was a higher incidence of tinea pedis among males than females in both age groups $(P=<0.005)$; the highest incidence occurring in adult males $(21.5 \%)$. The number of adults with verruca was small, but statistical analysis of the figures for juveniles showed a higher incidence among females than males $(P=<0.001)$.

TABLE II-Infection Rates According to Age and Sex

\begin{tabular}{|c|c|c|c|c|}
\hline & \multicolumn{2}{|c|}{ Adults } & \multicolumn{2}{|c|}{ Juven iles } \\
\hline & M. & F. & M. & F. \\
\hline $\begin{array}{l}\text { Total No. in sample .. } \\
\text { No. infected with } \\
\text { tinea pedis } \\
\text { No. infected with } \\
\text { verruca }\end{array}$ & $\begin{array}{c}205 \\
44 \\
(21 \cdot 5 \%) \\
2 \\
(1 \%)\end{array}$ & $\begin{array}{c}60 \\
2 \\
(3 \cdot 3 \%) \\
0 \\
(0 \cdot 0 \%)\end{array}$ & $\begin{array}{c}288 \\
18 \\
(6 \cdot 3 \%) \\
12 \\
(4 \cdot 2 \%)\end{array}$ & $\begin{array}{c}220 \\
2 \\
(0.9 \%) \\
23 \\
(10.5 \%)\end{array}$ \\
\hline
\end{tabular}

The dermatophytes isolated are shown in table III. The predominant species was Trichophyton mentagrophytes var. interdigitale which accounted for $62 \cdot 1 \%$ of all cases. T. rubrum $(13.6 \%)$ and Epidermophyton floccosum (10.6\%) were the other casual organisms, with two cases $(3 \%)$ of mixed infection and seven cases $(10.6 \%)$ diagnosed by microscopy only. There was no correlation between the age or sex of the infected person and the species of dermatophyte isolated.

TABLE III-Species of Dermatophytes Isolated from Tinea Pedis Infections

\begin{tabular}{|c|c|c|c|}
\hline & & $\begin{array}{l}\text { Total } \\
\text { Cases }\end{array}$ & (\% of Total) \\
\hline 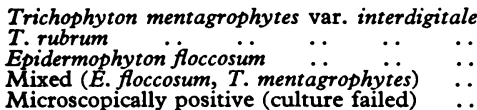 & $\begin{array}{l}\because \\
\therefore \\
\therefore\end{array}$ & $\begin{array}{r}41 \\
9 \\
7 \\
2 \\
7\end{array}$ & $\begin{array}{r}62 \cdot 1 \\
13 \cdot 6 \\
10 \cdot 6 \\
3 \cdot 0 \\
10 \cdot 6\end{array}$ \\
\hline
\end{tabular}

Infection rates among juveniles are analysed more closely in table IV, taking into account whether they attended with school classes or during free-swimming periods. The infection rate for tinea pedis was higher during free-swimming sessions $(5 \cdot 1 \%)$ than school sessions $(1.7 \%)(P=<0.1)$. The reverse was true for verruca with an incidence of $10.2 \%$ during school sessions and $5.1 \%$ during free-swimming periods $(P=<0.05)$. The highest incidence of verruca recorded $(19.6 \%)$ was among the group of 56 girls aged 7-11 years attending during school sessions.
TABLE IV-Effect of Environmental Factors on Incidence and Type of Foot Infection in fuveniles

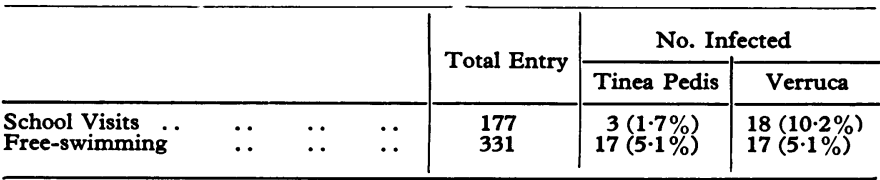

For tinea pedis the clinical and laboratory data did not always correlate. Peeling in the toe clefts, as the most severe symptom, was found in almost as many subjects $(41.1 \%)$ in the uninfected group as in the infected group $(45.5 \%)$. The incidence of more advanced clinical symptoms-namely, maceration, erythema, and fissures - was appreciably higher in those with tinea pedis; $33.3 \%$ compared with $8.5 \%$ in the uninfected group $(P=<0.001)$. Nevertheless, the number of clinically "normal" feet in the infected group was high (21.2\%), and in juveniles clinical abnormalities were more indicative of infection.

It was also found that only $12 \%$ of those with tinea pedis were aware of their infection and that $40 \%$ of adults and almost $70 \%$ of children did not know that communal bathing places were a common source of infection. Of those who knew of the dangers almost all children but only $75 \%$ of adults took some precautionary measure such as careful washing and drying of the feet or application of talcum powder after bathing; the others stated they knew of no procedure likely to be helpful.

There was a relation among juvenile males between the frequency of bathing and the incidence of tinea pedis $(P=$ $<0.025)$. Of the 288 boys $117(41 \%)$ swam at least once a week and $125(44 \%)$ more than once (some four or five times) a week, and in this latter group were $14(78 \%)$ of the 18 infections. For 220 girls the frequency of use was less, $101(46 \%)$ were weekly bathers and only $56(26 \%)$ attended more than once a week.

The incidence of tinea pedis could not be related to the use of shower facilities, other swimming pools, or service in the Forces. Almost everyone used the shower facilities, and in the age group 31-50 years, within which almost all persons with service in the Forces occurred, the proportion of the infected group who had been in the services was $78 \%$ (21 out of 27) compared with $77 \%$ (72 out of 94) of the uninfected group.

\section{Discussion}

The investigation was made specifically for the purpose of comparison with future surveys at this swimming bath after the introduction of measures aimed at reducing the spread of fungal infection. It is apparently the first survey of its kind, and in the absence of results for comparison it is not possible to say if the incidence of tinea pedis is higher in this group of subjects than in the population at large nor if these results are typical of swimming baths in general. Though almost $70 \%$ of the sample regarded themselves as regular bathers-that is, using the baths at least once a week-the duration for which they had been regular swimmers varied considerably and, moreover, the baths had been open for only 18 months at the time of the survey.

It is remarkable how similar our overall infection rates in adults of $17 \%$, in adult males of $21.5 \%$, and females of $3.3 \%$ are to the rates of $16.2 \%$ overall, $23 \%$ in males, and $4 \%$ in females found by English and Turvey (1968) in their survey of new patients at a chiropody clinic, which, as they suggested, is probably the nearest approach to a survey of tinea pedis in the adult population at large.

For juveniles our results are comparable with those of English and Gibson (1959 a) since most children in their 
survey also visited swimming baths either at school or public sessions or both. In their boys of 7-10 years of age they found $2.2 \%$ to be infected and this compares with $5.5 \%$ for our boys aged 7-11 years; for boys 11-14 years English and Gibson found an infection rate of $6.6 \%$ compared with $7.8 \%$ in our 12-15 years age group. These authors found that the availability and use of swimming baths was the only factor which could explain any variation in the incidence of infection, and among our boys, with $78 \%$ of infections among those who swam more than once a week, there can be no doubt of the relation between infection rates and frequency of bathing. For girls the frequency of use was less but the difference in infection rates between the sexes can hardly be related to the difference in regularity of bathing. It can, however, be related to opportunity for exposure. English and Gibson (1959 b) have shown clearly that dermatophytes are found most often in parts of baths used by populations with a high incidence of infection such as male changing rooms, and emphasized the importance of the "vicious circle of foot infection and floor contamination." Our results also indicate the importance and effect of exposure in that the transfer of infection apparently took place most of ten in changing rooms and shower stalls where the sexes do not mix. Moreover, a higher incidence of tinea pedis was found in juveniles examined during free-swimming sessions when adults were also present than at school sessions, and the overall incidence at weekends was $11.3 \%$ compared to $8.4 \%$ during weekdays. It should be noted that, in general, the regular swimmers attended on the same day(s) each week and that most children who were seen during school sessions attended the baths also at free-swimming sessions.

A predominance of foot infections with $T$. mentagrophytes var. interdigitale in various sections of the population was found by Gentles and Holmes (1957) for coal miners using pit head baths in various parts of Britain, by English and Gibson (1959 a, 1959 b) for children, Walshe and English (1966) in toenail infections of adults in Bristol, and by English and Turvey (1968) for adults in London. It is not therefore surprising that this species comprised more than $60 \%$ of our isolates. Our proportions of the three species of dermatophytes isolated from adults conforms closely to that reported by English and Turvey (1968) and isolations from juveniles agree closely with the proportions found by English and Gibson (1959 a).

It was found as reported by previous investigators (Holmes and Gentles, 1956; English and Gibson, 1959 b) that clinical criteria are unsatisfactory for diagnosis of tinea pedis. Moreover, relatively few infected bathers were aware of their in- fections. More disturbing, however, is the proportion of people who are unaware of the dangers of communal bathing and the failure of a number of those who do know of the risks to take precautions. There would appear to be a need for publicity and instruction.

The opportunity to make this investigation arose because of complaints of foot infections allegedly contracted at the swimming baths. Though tinea pedis was involved the major complaint was of the sudden increase in the incidence of verruca, and this condition was therefore noted during our examination. The overall incidence of verruca in our juveniles $(6.9 \%)$ is higher than recorded in any previous surveys of this condition in schoolchildren, despite the fact that in an unknown number of instances children were excluded from school swimming sessions because of their verrucae. Allen and Dickinson (1968) found an overall incidence of $2.5 \%$ but there was no difference in prevalence according to sex. They did find, however, that the incidence of verrucae was higher in children who frequented heated covered swimming pools $(4.0 \%)$ than among those using open-air pools $(2.5 \%)$. In other surveys Hollman (1969) found an incidence of $1.0-2.0 \%$ and Tranter (1969) of $1 \cdot 0-3.0 \%$. The latter also found a positive relation between the frequency of swimming and the incidence of verrucae. Our findings indicate that the involvement of the swimming baths in the spread of infection and the "vicious circle" of infection and floor contamination emphasized by English and Gibson (1959 b) for tinea pedis clearly applies for this disease also, since the incidence was higher during school visits $(10.2 \%)$ than at public swimming sessions $(5.1 \%)$ and in girls $(10.5 \%)$ than in boys $(4 \cdot 2 \%)$.

We are greatly indebted to the staff of the swimming bath, to the medical officer of health of the town concerned and his staff for their help and co-operation, and to Glaxo Laboratories Ltd. for material support.

\section{References}

Allen, W. H., and Dickinson, V. A. (1968). Medical Officer, 119, 261. English, M. P., and Gibson, M. D. (1959 a). British Medical fournal, 1, 1442. English, M. P., and Gibson, M. D. (1959 b). British Medical fournal, 1, 1446.

English, M. P., and Turvey, J. (1968). British Medical fournal, 4, 228.

Gentles, J. C., and Holmes, J. G. (1957). British Fournal of Industrial Medicine, 14, 22.

Hollman, C. E. (1969). Medical Officer, 121, 313.

Holmes, J. G., and Gentles, J. C. (1956). Lancet, $2,62$.

Tranter, A. W. (1969). Medical Officer, 121, 317. Walshe, M., and English, M. P. (1966). British fournal of Dermatology, 78,
198. 